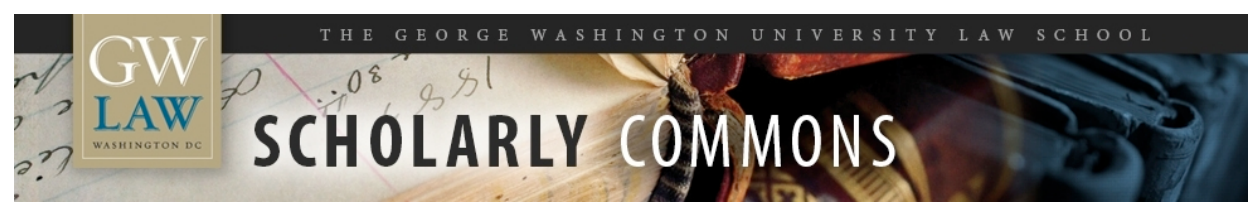

\title{
The Inherent Tension Between Value Creation and Value Claiming During Bargaining Interactions
}

Charles B. Craver

George Washington University Law School, ccraver@law.gwu.edu

Follow this and additional works at: https://scholarship.law.gwu.edu/faculty_publications

Part of the Law Commons

\section{Recommended Citation}

Craver, Charles B., "The Inherent Tension Between Value Creation and Value Claiming During Bargaining Interactions" (2011). GW Law Faculty Publications \& Other Works. 474.

https://scholarship.law.gwu.edu/faculty_publications/474

This Article is brought to you for free and open access by the Faculty Scholarship at Scholarly Commons. It has been accepted for inclusion in GW Law Faculty Publications \& Other Works by an authorized administrator of Scholarly Commons. For more information, please contact spagel@law.gwu.edu. 


\title{
THE INHERENT TENSION BETWEEN VALUE CREATION AND VALUE CLAIMING DURING BARGAINING INTERACTIONS
}

\author{
Charles B. Craver*
}

\section{INTRODUCTION}

When individuals negotiate, they often assume a "fixed pie." They believe that whatever they want, the other side values equally. As a result, each item traded generates a plus score for the recipient of that term that is offset by a commensurate loss by the other party. ${ }^{1}$ A classic example involves a lawsuit where the only issue in dispute concerns the amount of money the defendant will pay to the claimant. If the plaintiff receives $\$ 100,000$, the defendant loses $\$ 100,000$. If the claimant obtains $\$ 500,000$, the defendant loses $\$ 500,000$. These situations are frequently referred to as "zero sum" interactions.

Competitive/Adversarial "win-lose" litigators tend to view almost all settlement discussions as zero sum endeavors, ignoring the possibility for joint gains. ${ }^{2}$ For example, a patient who has filed a medical malpractice lawsuit resulting from serious treatment complications may seek only monetary compensation. If she demands immediate cash payment of a specific amount, the interaction will truly be zero sum. On the other hand, if she agrees to accept payments over a number of years, the overall pie may be expanded in several critical ways. If some of the damages covers lost earnings over a number of years, a lump sum may be taxable at a higher rate than smaller amounts paid out over several years. The parties may alternatively characterize more of the money being exchanged as compensation for pain and suffering associated with physical injuries that are not taxable under section 104(a) of the Tax Code. ${ }^{3}$ In addition, when future payments are made, the defendant can set

* Freda H. Alverson Professor, George Washington University Law School. J.D., 1971, University of Michigan; M. Indus. \& Lab. Rels., 1968, Cornell University School of Indus. \& Labor Rels.; B.S., 1967,

1 See Leaf Van Boven \& Leigh Thompson, A Look into the Mind of the Negotiator: Mental Models in Negotiation, in 6 Group Processes \& Intergroup Relations 387, 388 (2003).

2 Roger Fisher \& William Ury, Getting to Yes 61 (1983).

326 U.S.C. $\$ 104(\mathrm{a})(1)$ (2000). 
money aside and invest it in stocks or bonds that will generate dividends or interest until the sums have to be transferred to the claimant. A substantial portion of the settlement amount may cover corrective medical services. If the defendant agrees to provide those services, both sides may benefit. What might have cost the claimant $\$ 20,000$ to obtain from other medical providers may only cost the defendant $\$ 12,000$ to provide, generating savings of $\$ 8,000$.

The defendant may value a confidentiality provision precluding the disclosure of any aspects of the settlement agreement to protect its reputation, and it may be willing to pay extra to obtain such a clause. Similarly, the defendant may agree to pay more for a non-admission provision indicating that the settlement does not constitute an admission of fault on its behalf. The claimant may value a sincere apology from the responsible party, and would lower her monetary demand if she is presented with one. The defendant may be willing to pay an extra $\$ 20,000$ to $\$ 25,000$ for the confidentiality provision and an equal amount for the confidentiality clause. On the other hand, the plaintiff may be willing to accept $\$ 25,000$ less if she receives an apology. Thus, these three terms could generate a joint surplus approaching $\$ 75,000$.

Transactional negotiators seeking a buy-sell contract, considering a possible joint venture agreement, or contemplating a licensing arrangement pertaining to new technology usually have a number of different issues to be resolved. If the parties view their interaction as zero sum, they are likely to engage in an adversarial exchange, as each side endeavors to obtain the best results for itself. Such an approach will not only make the interaction less pleasant and more difficult, but will also threaten future relations between the negotiating parties.

A typical buy-sell interaction may initially appear to be a zero sum transaction, with the buyer giving up an amount equal to what the seller is obtaining. Nonetheless, parties involved in such discussions should look for ways to expand the pie. The seller may agree to accept $\$ 50$ million paid out over ten years, or some remuneration in the form of stock in the purchasing firm. The purchasing corporation may agree to pay $\$ 40$ million in cash and provide $\$ 12$ million in goods and services. Although the seller thinks it got paid $\$ 52$ million, the buyer only paid $\$ 47$ million. The $\$ 5$ million difference is based upon the fact that the goods and services valued at $\$ 12$ million by the seller only cost the buyer $\$ 7$ million to generate. 
When parties enter into a licensing agreement, different issues must be addressed. How much money will be paid when the contract is executed? How expansive will the license contract be? Will it be exclusive or non-exclusive? Will it have global scope or more limited geographic coverage? How long will the license term operate? What will be the royalty rate? As the parties discuss these issues, they must try to determine which terms the licensor and licensee value most. By achieving an efficient agreement which maximizes the joint gains achieved by both sides, the parties can expand the pie and generate a meaningful surplus.

When negotiating parties interact, they must work to ascertain possible ways to expand the overall pie-they should not simply assume zero sum situations. The greater the overall value of issues to be shared, the greater the likelihood that both sides will achieve beneficial results. As they begin to discover the potential for joint gains, the parties must decide how to divide the generated surplus. Many persons naively think that the parties should equally share the surplus. In reality, however, most interactants are likely to use distributive bargaining techniques to claim more of the surplus for their own side. What makes this issue more complex is the fact that the negotiating parties rarely know how much surplus has actually been created, which makes it impossible to know precisely how much each side is taking. In addition, one party may desire a successful transaction more than the other, and thus be willing to give up more than half of the surplus to guarantee an overall agreement.

When negotiators look for ways to expand the overall pie and create joint surplus, they must indicate the items they desire, the interests underlying those issues, and the degree to which they value those terms. Nonetheless, they may not be entirely forthright. If Side A highly values Item 5, but thinks that Side B does not consider that term significant, Side A may understate the degree to which it wants Item 5, hoping it will not have to give up very much to obtain it. Similarly, if Side B thinks that Side A really wants Item 5, Side B may suggest that this term is vital to it, hoping to induce Side A to make a significant concession to obtain that term. Once the surplus has been generated, parties may similarly employ disingenuous bargaining tactics to claim a greater share of that surplus.

[E]ven within the range of circumstances in which there are significant opportunities for integrative bargaining, the bargainer must almost always engage in distributive bargaining as well. 


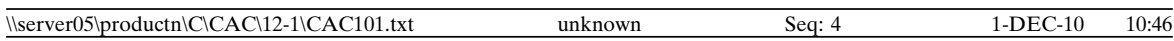

\section{CARDOZO J. OF CONFLICT RESOLUTION [Vol. 12:101}

Therefore, it is in the bargainer's self-interest not just to adopt the tactics of openness and truth-telling that are said to be appropriate for integrative bargaining, but somehow also to adopt the tactics of truth-hiding and dissimulation that are said to be appropriate to distributive bargaining. ${ }^{4}$

This article will discuss the inherent tension present in almost all legal and commercial negotiations between value creation and value claiming. How should interactants use integrative techniques to discover areas for potential joint gains, and how should they determine the actual value of the gains achieved? The article will then explore the way in which proficient negotiators employ distributive tactics to claim a greater share of the surplus for themselves. Before we examine those issues, however, we must consider different negotiator styles and the ways in which those styles influence value creation and value claiming.

\section{Negotiator styles}

Most negotiation experts tend to divide negotiators into two opposite stylistic groups: Cooperative/Problem-Solvers and Competitive/Adversarials. The most extensive studies of legal negotiator styles were conducted in 1976 by Gerald Williams ${ }^{5}$ and in 1999 by Andrea Schneider. ${ }^{6}$ Cooperative/Problem-Solvers move psychologically toward their opponents, work to maximize the joint returns achieved, begin with realistic opening offers, seek fair results, behave courteously and professionally, are open and trusting, rarely resort to threats, rely upon objective standards, and reason with their adversaries. ${ }^{7}$ Competitive/Adversarials move psychologically against their opponents, seek to maximize their own side returns, begin with more extreme opening positions, seek more extreme results favoring their own side, behave less courteously, and are closed, untrusting, and manipulative. ${ }^{8}$ Competitive/Adver-

4 Gerald B. Wetlaufer, The Limits of Integrative Bargaining, 85 GEO. L. J. 369, 390-91 (1996).

5 See generally Gerald R. Williams, Legal Negotiation and Settlement (1983).

6 See generally Andrea Kupfer Schneider, Shattering Negotiation Myths: Empirical Evidence on the Effectiveness of Negotiation Styles, 7 Harv. Negot. L. Rev. 143 (2002).

7 See Charles B. Craver, Effective Legal Negotiation and Settlement 9-10 (6th ed. 2009).

$8 I d$. 
sarial negotiators frequently conceal their negative information and overstate their positive information. ${ }^{9}$

Professor Williams conducted his study with attorneys in Phoenix. He asked lawyers not to classify themselves, but to characterize the styles of attorneys with whom they had recently interacted. Almost two-thirds of legal practitioners were classified as Cooperative/Problem-Solvers, one quarter as Competitive/Adversarials, and eleven percent remained unclassified. ${ }^{10}$ Professor Williams asked the individuals in his study to indicate which of the persons involved were effective, average, or ineffective negotiators. ${ }^{11}$ Fifty-nine percent of the Cooperative/Problem-Solvers were considered effective, thirty-eight percent average, and three percent ineffective. ${ }^{12}$ Only twenty-five percent of Competitive/Adversarial negotiators were rated effective, with forty-two percent rated average and thirty-three percent rated ineffective. ${ }^{13}$

When Professor Schneider replicated Professor Williams' empirical study in 1999 with attorneys in Milwaukee and Chicago, she found that sixty-four percent were characterized as Cooperative/ Problem-Solvers and thirty-six percent were described as Competitive/Adversarials. ${ }^{14}$ Fifty-four percent of the Cooperative/Problem-Solvers were considered effective negotiators, forty-two percent average, and four percent ineffective. ${ }^{15}$ Only nine percent of the Competitive/Adversarials were considered effective negotiators, thirty-eight percent average, and fifty-three percent ineffective. ${ }^{16}$

The studies conducted by Williams and Schneider suggest that most effective negotiators employ a Cooperative/Problem-Solving style which generates complete openness and an effort to maximize the joint returns obtained by the parties. Nonetheless, when their findings are examined more closely, it becomes clear that many effective negotiators are actually wolves in sheep clothing. Williams and Schneider asked the effective bargainers from both groups to disclose their primary objectives in their interactions with others. The primary goal for effective Competitive/Adversarials was to

\footnotetext{
9 Id.

10 See Williams, supra note 5, at 19.

11 See id.

$12 \mathrm{Id}$.

$13 I d$.

14 See Schneider, supra note 6, at 163.

15 See id. at 167, 189.

16 Id.
} 
maximize their own returns, ${ }^{17}$ which is the classic objective of competitive negotiators. When effective Cooperative/Problem-Solvers were also questioned about their main objectives, they indicated that their second objective-just behind a wish to maintain high ethical standards-was the maximization of their own side's returns. ${ }^{18}$ A more comprehensive evaluation of these factors has caused Professor Williams and myself to conclude that there is a hybrid negotiating style that falls between the Cooperative/Problem-Solving and Competitive/Adversarial approaches and combines the optimal characteristics of both. ${ }^{19}$

Competitive/Problem-Solvers are individuals who strive for competitive objectives-maximization of their own side's returnsbut work to accomplish this goal in a non-adversarial way. ${ }^{20}$ Once they obtain most of what they hope to achieve for their own clients, they work to maximize the returns attained by their opponents. ${ }^{21}$ These individuals are more open than Competitive/Adversarials, but less forthcoming than conventional Cooperative/Problem-Solvers. ${ }^{22}$ They generally disclose the terms they hope to obtain, knowing that such disclosures are important if jointly efficient accords are to be achieved, but they over- and under-state the degree to which their clients want those items for strategic purposes. ${ }^{23}$

When Competitive/Problem-Solvers negotiate with naïve Cooperative/Problem-Solvers, they work to exploit their opponent's openness. $^{24}$ They actually endeavor to create value during the Information Stage in the Getting to Yes $^{25}$ tradition, but they are not entirely forthcoming. They may over- or under-state the value of items they desire to subsequently enable them to obtain more highly valued terms for less; this may also enable them to attain more from opponents when they concede issues that side values but erroneously thinks this side also considers important. ${ }^{26}$ As the parties move into the Distributive Stage, they similarly employ

\footnotetext{
17 See Williams, supra note 5, at 23; Schneider, supra note 6, at 179.

18 See Williams, supra note 5, at 20; Schneider, supra note 6, at 169.

19 Gerald R. Williams \& Charles B. Craver, Legal Negotiating $64-65$ (2007).

20 See id.

21 Id.

$22 I d$.

$23 I d$.

24 See Steven Hartwell, Understanding and Dealing With Deception in Legal Negotiation, 6 Ohio St. J. on Disp. Resol. 171, 173-75, 185-86 (1991).

25 Fisher \& URY, supra note 2.

26 See Williams \& CRaver, supra note 19, at 64-65.
} 
subtle, manipulative tactics in order to enable them to claim more of the joint surplus than they give to their opponents. ${ }^{27}$

[E]ven within the range of circumstances in which there are significant opportunities for integrative bargaining, the bargainer must almost always engage in distributive bargaining as well. Therefore, it is in the bargainer's self-interest not just to adopt the tactics of openness and truth telling that are said to be appropriate to integrative bargaining, but somehow also to adopt the tactics of truth-hiding and dissimulation that are said to be appropriate to distributive bargaining. ${ }^{28}$

Unsuspecting negotiators do not understand how manipulative and disingenuous Competitive/Problem-Solvers can be. As a result of the apparent openness of Competitive/Problem-Solvers, their opponents usually think they are Cooperative/Problem-Solvers. Since negotiators often believe these individuals are being entirely candid, they volunteer their own confidential bargaining information without realizing that their openness is not being equally reciprocated. ${ }^{29}$ They are certain that these persons are working to generate "win-win" results, when they are really endeavoring to obtain "WIN-win" distributions favoring their own side. $^{30}$

If we negotiators were seeking truly equal terms and deals, like King Solomon, we'd simply divide everything in half. In reality, we're out to achieve all (or most) of our goals, to make our most desirable deal. But the best way to do so is to let the other side achieve some of their goals, to make their acceptable deal. That's WIN-win: big win for your side, little win for theirs. ${ }^{31}$

When Keith Allred conducted empirical studies of the traits associated with successful negotiators, he found this hybrid ap-

$27 I d$.

28 Wetlaufer, supra note 4, at 372. See also Robert J. Condlin, Bargaining With a Hugger: The Weaknesses and Limitations of a Communitarian Conception of Legal Dispute Bargaining, or Why We Can't All Just Get Along, 9 Cardozo J. Conflict Resol. 1, 65-66 (2007); Raymond A. Friedman \& Debra Shapiro, Deception and Mutual Gains Bargaining: Are They Mutually Exclusive? 11 Negot. J. 243, 247-250 (1995).

29 See Catherine H. Tinsley et al., Reputations in Negotiation in The Negotiator's Fieldbook 203, 207-08 (Andrea Kupfer Schneider \& Christopher Honneyman, eds., 2006) (indicating how much more open Cooperative/Problem-Solvers are when they believe they are interacting with other Cooperative/Problem-Solvers).

30 Id.

31 Ronald M. Shapiro \& Mark A. Jankowski, The Power of Nice 5 (2001) (emphasis in original). 
proach particularly effective. ${ }^{32}$ He analyzed the degree to which adept bargainers used "strategic practices" designed to enable them to claim more of the joint surplus for themselves and "accommodating practices" designed to maximize the joint returns attained. ${ }^{33}$ Allred discovered that the most proficient negotiators were considered by their adversaries to employ primarily "accommodating practices," even though these bargainers admitted that they actually used "strategic practices" that would enable them to best advance their own interests. ${ }^{34}$ In fact,

[h]aggling permits bargainers to learn about, adjust to, and accommodate the interests of other bargainers. It permits them to change minds, weaken convictions, make trades, call attention to facts not fully considered, revive arguments dismissed prematurely, and express the nature of their interests and the intensity of their resolve. ${ }^{35}$

The findings by Professors Williams and Schneider strongly indicate that many lawyers who appear to follow the Cooperative/ Problem-Solving approach may subtly employ Competitive/Adversarial techniques to advance their interests. ${ }^{36}$ Although they do not commence bargaining interactions with the more extreme positions articulated by classic Competitive/Adversarials, they do not open with the truly reasonable positions taken by real Cooperative/ Problem-Solvers. They instead start with partially overstated demands or under-stated offers, hoping to establish beneficial anchoring points. ${ }^{37}$ They usually acknowledge their actual objectives, but frequently over- or under-state the degree to which they desire those items. They do a good job of creating value by getting the underlying interests of both sides on the bargaining table. Once that is accomplished, however, they cleverly use manipulative tactics that enable them to claim more than their fair share of the joint surplus.

Competitive/Problem-Solvers are successful, because they recognize the fact that most negotiators judge their satisfaction with bargaining outcomes more by the degree to which they believe the

32 See Keith G. Allred, Distinguishing Best and Strategic Practices: A Framework for Managing the Dilemma Between Creating and Claiming Value, 2000 Negot. J. 387, 394-395 (2000).

33 Id.

34 Id.

35 Robert J. Condlin, "Every Day and in Every Way We Are All Becoming Meta and Meta," or How Communitatian Bargaining Theory Conquered the World (of Bargaining Theory), 23 Онiо St. J. Disp. Res. 231, 268 (2008).

36 See Williams, supra note 5, at 27; Schneider, supra note, at 188.

37 See Craver, supra note 7, at 56-57. 
process was fair and respectful than by the objective value of the terms obtained. ${ }^{38}$ Competitive/Problem-Solver negotiators are personable and respectful. They avoid overtly competitive behavior, and act as if they are Cooperative/Problem-Solvers. Their adversaries are so appreciative of their seemingly open and courteous conduct that they over-value the actual worth of the terms they obtain.

During the value creation portion of bargaining interactions, Competitive/Problem-Solvers learn more about opponent values and interests than they disclose with respect to their own values and interests. This provides them with a significant advantage once the parties begin to divide the joint surplus which has been created. Through the use of subtle distributive techniques, they are able to claim more of the surplus than their unsuspecting opponents ever imagine.

\section{Value Creation}

Many contemporary dispute resolution professionals associate the integrative bargaining "win-win" concept with Roger Fisher \& William Ury. ${ }^{39}$ As Fisher and Ury recognize in their Acknowledgments, however, the basic concept had been developed eighty years earlier by Mary Parker Follett who became a business consultant in the early 1900s and developed the integrative bargaining model for her corporate clients. ${ }^{40}$ This important concept achieved more expansive scholarly and academic recognition with the publication of A Behavioral Theory of Labor Negotiations in $1965 .{ }^{41}$

The classic example of integrative or cooperative bargaining involves two sisters who wanted the same orange. ${ }^{42}$ They argue about the orange until they finally agreed to cut it in half and share it equally. Only later do they discover that one wants the pulp to eat while the other wants the peel for baking. They made the mistake of assuming that they both wanted the same thing. Had one

38 See Rebecca Hollander-Blumoff \& Tom R. Tyler, Procedural Justice in Negotiation: Procedural Fairness, Outcome Acceptance, and Integrative Potential, 33 LAW AND Soc. InQuiry 473 (2008); Nancy A. Welsh, Perceptions of Fairness in The Negotiator's Fieldbook 165, 170-71 (Andrea Kupfer Schneider \& Christopher Honeyman, eds., 2006).

39 FISHER \& URY, supra note 2.

40 See Joan C. Tonn, Mary P. Follett 360-388 (2003).

41 Richard E. Walton \& Robert B. McKersie, A Behavioral Theory of Labor NeGOTIATIONS (1965).

42 See Fisher \& URy, supra note 2, at 76. 
simply asked the other "why do you want the orange," they would have discovered that they had no conflict. One should have been given all of the fruit with the other receiving all of the rind.

What the orange example naively assumes is that in many bargaining situations, the parties have non-conflicting interests. If there are ten items to be divided, Side A values Items 1, 3, 5, 7, and 9, while Side B values Items 2, 4, 6, 8, and 10 . The solution is to make sure each side gets the five items it desires. Such a situation almost never arises in legal or commercial negotiations. ${ }^{43}$ There may be items that only Side A desires and other items that only Side B desires - the "cooperative" terms—but there will generally be items that both sides wish to obtain-the "distributive" terms.

The classic distributive issue with respect to legal and commercial interactions concerns money. I have never had a client who indicated that he, she, or it did not care about money, whether they had to give it up or were trying to obtain it. Some may have valued it more or less than others, but every single one considered money to be a significant factor. Other terms may be equally contested. A person harmed by the wrongful behavior of another party may wish to obtain a public acknowledgment of responsibility, while the responsible actor may want a nonadmission provision and a confidentiality clause. The purchaser of a business may want a warranty against known and unknown environmental difficulties, while the seller may be opposed to any such warranty with respect to unknown conditions. Divorcing spouses may each wish to obtain sole residential custody of their two minor children. Although compromises on these issues may be achieved through the negotiation process, one side's gain will generally be considered the other side's loss.

If negotiators hope to achieve efficient agreements that maximize the joint returns achieved, they must appreciate the benefits that may be derived from integrative bargaining and must explore the way in which each side values the different items involved. Which items are desired by one side but not the other? Which items do both parties wish to have resolved in the identical manner? Which terms do both sides value - and how much does each wish to obtain these items?

The terms desired by only one party should clearly end up on that side of the bargaining table. The terms the parties wish to have resolved the same way should be handled in that manner.

43 See Russell Korobkin, Against Integrative Bargaining, 58 CASE W. Res. L. Rev. 1324 (2008). See generally Condlin, supra note 28. 
The issues that both sides value will be the terms that both endeavor to claim - but they should still focus on efficiency considerations. Which of these items are considered "essential" by Side A, but only "important" or "desirable" by Side B, and vice versa? Which are "important" to Side A, but only "desirable" to Side B, or vice versa? Which are valued equally by both sides as essential, important, or desirable? ${ }^{44}$

During the value creation portion of bargaining interactions, negotiators must try to ascertain the relative values of the items to be exchanged. The optimal way to obtain the relevant information is through the questioning process. Proficient negotiators ask more questions than their less adept cohorts, ${ }^{45}$ and they know how to employ "what" and "why" inquiries. ${ }^{46}$ "What" questions are posed in an effort to discover the different terms valued by the opposing side. "Why" questions are posed to determine the other side's interests underlying those terms.

Once individuals have thoroughly prepared for a negotiation, they begin to interact with their opponents. This is the Preliminary Stage where the participants try to establish rapport with each other and to create a positive negotiation environment. ${ }^{47}$ At the commencement of their interaction, the interactants should use small talk and look for common interests to enable them to develop beneficial working relationships. This decreases the likelihood that either side will behave badly once they get into the substantive discussions. The parties should also strive to create positive environments, thereby increasing the likelihood the participants will behave more cooperatively, reach more agreements, and achieve more efficient arrangements. ${ }^{48}$

Once the Preliminary Stage is finished, the parties enter the Information Stage, which is the value creation part of their interaction. ${ }^{49}$ This is where most questions are posed. Even if the participants are integrative bargainers who seem committed to cooperative interactions, distributive tendencies may influence ne-

\footnotetext{
44 See Craver, supra note 9, at 94-95.

45 See Hal Movius, The Effectiveness of Negotiation Training, 24 Negot. J. 509, 513-14 (2008).

46 See Deepak Malhotra \& Max H. Bazerman, Negotiation Genius 85-86 (2007).

47 See Craver, supra note 7, at 65-72.

48 See Robert B. Lount, Jr., The Impact of Positive Mood on Trust in Interpersonal and Intergroup Interactions, 98 J. Personality \& Soc. Psychol. 420, 421-22 (2010); Joseph Forgas, On Feeling Good and Getting Your Way: Mood Effects on Negotiator Cognition and Bargaining Strategies, 74 J. Personality \& Soc. Psychol. 565, 566-74 (1998).

49 See Craver, supra note 9, at 73-97.
} 
gotiator behavior. The participants may be willing to disclose most - and perhaps even all—of the items they value, but they may not be entirely forthright. They may decide to over- or under-state the value of different terms for strategic purposes. For example, if they value a particular item highly but believe that the other side does not care about this term, they may downplay the true significance of this item. This practice is done with the hope of obtaining it without having to concede much to the other side. Similarly, if they do not value an item they are certain the other side really wants, they may overstate the degree to which they value it hoping to obtain a significant concession for it.

Are such deceptive tactics unethical for legal representatives? Model Rule 4.1 states that "a lawyer shall not knowingly make a false statement of material fact or law to a third person." 50 This provision appears to proscribe negotiator misrepresentations that pertain to client interests and values. Nonetheless, when Rule 4.1 was being drafted, persons who teach negotiation skills noted the types of "innocent" misstatements frequently made during bargaining interactions with respect to actual client values and settlement objectives. As a result, Comment 2 was included to expressly exempt representations pertaining to such issues.

Whether a particular statement should be regarded as one of fact can depend on the circumstances. Under generally accepted conventions in negotiation, certain types of statements ordinarily are not taken as statements of material fact. Estimates of price or value placed on the subject of a transaction and a party's intentions as to an acceptable settlement of a claim are ordinarily in this category, . . .

Thus, it is clear that legal representatives may ethically over- and under-state client values with respect to the different items being exchanged, since such information does not constitute "material fact" under Rule 4.1. Further, Comment 2 allows attorneys to over- or under-state client settlement intentions, enabling them to demand more or offer less than the clients are actually willing to accept or pay. ${ }^{52}$

The innate distributive aspect of almost all legal and commercial negotiations creates the inherent tension between value crea-

\footnotetext{
50 Thomas D. Morgan \& Ronald D. Rotunda, 2008 Selected Standards on ProfesSiONAL RESPONSIBILITY 92 (2008).

51 Id. at 93.

52 See generally Charles B. Craver, Negotiation Ethics for Real World Interactions, 25 Онго ST. J. ON Disp. Resol. 299 (forthcoming 2010).
} 
tion and value claiming. Truly Cooperative/Problem-Solving Negotiators, who naively disclose all of their true values and interests to what are actually Competitive/Problem-Solving opponents who are not really reciprocating their candor, place themselves and their clients at a distinct disadvantage. If they are wholly open while their manipulative adversaries are not, they generate an information imbalance which can be exploited by adept opponents. Their disingenuous adversaries can over- and under-state their actual values with respect to the different issues, and they can overand under-state their true settlement intentions. It is as if they are playing poker with their cards face up, while their opponents are permitted to hide some of their cards. By the end of the interaction, the entirely open participants are likely to obtain far less of the surplus discovered than their manipulative adversaries.

Naturally Cooperative/Problem-Solvers should be careful when they initially enter the Information Stage. They should slowly release some of their confidential information pertaining to client values and wait to see if their candor is being reciprocated. If they are confident that the other side is being as forthcoming, they can continue their openness. On the other hand, if they begin to suspect that the other side is not being as forthcoming, they need to be more circumspect. They should change their negotiation style and not be as open. They should still indicate the items their side wishes to obtain, but not be too candid with respect to the degree to which they desire those terms. They may decide to overor under-state the value of items to avoid exploitation by Competitive/Problem-Solvers who are using subtly manipulative tactics to obtain more information and to ultimately claim more of the joint surplus which exists.

If bargainers are overly deceptive, however, the participants may be unable to achieve accords that should have been reached, and the agreements generated may be inefficient due to the interactants' inability to discover and jointly exploit the different degrees to which they value the underlying issues. Both sides will leave potential client satisfaction on the bargaining table. It thus behooves bargainers not to be too deceptive during the Information Stage. They should generally indicate the items they would like to obtain. If they fail to do so, the other side may never offer to provide them with these terms.

Negotiators should similarly not over- or under-state the value of items so greatly that the parties miss the opportunity to generate joint gains and to formulate more efficient agreements. They do 


\section{CARDOZO J. OF CONFLICT RESOLUTION [Vol. 12:101}

not want to see items that one side considers to be "essential" or "important" end up in the hands of the party that only considers those items to be "desirable." The party that places a greater value on particular terms should obtain those provisions in exchange for issues the other side values more highly than this side.

\section{Value Claiming}

After negotiators use the Information Stage to determine the divisible items and an approximate understanding of the relative degree to which each side values the different terms, they enter the Distributive Stage during which they endeavor to achieve a mutual accord. ${ }^{53}$ This is a highly competitive part of the bargaining process, because no clear principles dictate the manner in which the joint surplus should be divided. Should the discovered surplus be divided equally or equitably? If the participants possess identical bargaining power and equal bargaining proficiency, a relatively equal sharing of the surplus might be appropriate. The difficulty concerns the fact that opponents are rarely situated so equally. One side tends to possess more economic power than the other and/or greater bargaining skill. In such circumstances, a truly egalitarian distribution would be a windfall to the weaker or less adroit participant.

Despite the objections of some theoretical academics, most practicing attorneys would suggest an equitable division of the pertinent items that reflects the comparative power and negotiating prowess of the interactants. Even this objective is not easily attainable, due to the use of disingenuous tactics designed to enable the more manipulative participant to claim an excessive share of the joint surplus. She may establish an artificial deadline to induce a more risk averse opponent to cave in to her demands. She may employ real or feigned threats of litigation or a cessation of talks to generate excessive opponent concessions. She may imply that she has other options she could accept if this party does not provide her side with sufficiently generous terms.

This latter approach may raise substantial ethical issues. For example, assume a client hopes to sell his business for $\$ 10$ million, but would be willing to accept $\$ 8.5$ million if necessary. His representative could begin the discussions with a demand for $\$ 12$ mil-

53 See Craver, supra note 7, at 99-126. 
lion, $\$ 15$ million, or even $\$ 20$ million, to anchor the discussions with an elevated position statement. Could she ethically indicate that her client has an offer from a third party to purchase his firm when he has received no such offer? I believe the answer is clearly "no," because this would constitute a misrepresentation of material fact proscribed by both Model Rule 4.1 and basic principles of fraud. If the owner has an offer from a third party for $\$ 8$ million, could his attorney indicate that they have a $\$ 10$ million offer? I think that such an exaggeration would similarly contravene Rule 4.1 and expose her client to a claim for fraudulent misrepresentation. On the other hand, it would probably be acceptable for the seller's representative to indicate (truthfully) that they have another offer, and suggest that this prospective buyer will have to pay $\$ 10$ million if they wish to purchase the company. In this instance, the exaggeration would merely reflect client settlement intentions that are excluded from the scope of Rule 4.1 due to the exception set forth in Comment 2.

During the Distributive Stage, most legal and commercial negotiators use implied or overt threats, time pressure, and various manipulative bargaining tactics ${ }^{54}$ to obtain more favorable terms for their own side than they might objectively deserve. I see this demonstrated regularly by students in my Legal Negotiation course and in the continuing legal education programs I conduct for state bar associations and for specific law firms. The results achieved on the distributive terms of my practice exercises vary widely. I have one exercise where the monetary payments range from $\$ 250,000$ to over $\$ 2$ million. I have another where the monetary range is from $\$ 0$ to over $\$ 250,000$.

Before readers surmise that the existence of significant differences with respect to these distributive terms means that the participants have achieved inefficient accords, I must note that my law students learn how to fight over the distributive items while they simultaneously work to achieve efficient distributions of the cooperative terms. This is true whether the negotiators are particularly cooperative or competitive. The naturally cooperative interactants strive for efficient and fair terms, while the naturally competitive individuals seek efficient, but more one-sided arrangements. Even the competitive persons realize, however, that if they are inefficient with respect to the cooperative terms, they will be less likely to obtain as much of the distributive issues. They thus work diligently to ascertain the non-distributive needs of their opponents and to

54 See id. at $145-179$. 


\section{CARDOZO J. OF CONFLICT RESOLUTION [Vol. 12:101}

satisfy those desires. They do not do this because of altruistic considerations. They instead appreciate the fact that if they provide their adversaries with what those parties require in these areas, it will be easier for them to obtain more of the distributive surplus which has been created. Although my student agreements vary widely with respect to the distributive terms agreed upon, I am amazed by their ability to divide the cooperative items in a way that generates the most joint surplus. This is a practice legal representatives should always follow if they hope to achieve fair-or even unbalanced-final terms.

An empirical study conducted by Professors Kathleen O'Connor and Peter Carnevale supports my observations with respect to my Legal Negotiation students. ${ }^{55}$ Their study concerned "common-value issues" that both sides wished to have resolved in the same fashion even though they were not aware of their positional overlap. Some of the bargaining pairs were entirely open and cooperative with respect to their interests, while other dyads included negotiators who could be disingenuous with respect to their true interests. O'Connor and Carnevale found that the individualistically motivated pairs achieved higher joint outcomes than the cooperatively motivated pairs. This was apparently due to the fact that individualistically motivated negotiators established higher overall objectives for themselves than did the cooperatively motivated participants, and the individualistically motivated persons recognized that by generating the most efficient overall agreements, they increased their chances of obtaining optimal results for themselves.

Once negotiating parties have achieved agreements, how can they be certain they have generated efficient accords? The best way is to move into the Cooperative Stage ${ }^{56}$ before they conclude their interactions. Prior to the time they enter this stage, however, they should be certain they have reached definitive accords. They should review the different provisions agreed upon to be sure there are no misunderstandings. Near the conclusion of the Distributive Stage, negotiating parties frequently move expeditiously to close the remaining gaps. One side may have thought the other side was conceding more than it intended or took something off the table it did not mean to eliminate. If they discover such misunderstandings

55 See Kathleen M. O'Connor \& Peter J. Carnevale, A Nasty But Effective Negotiation Strategy: Misrepresentation of a Common-Value Issue, 23 Personality \& Soc. Psychol. Bulletin 504 (1997).

56 See Craver, supra note 7, at 133-143. 
now, they are psychologically committed to an agreement and will usually find a way to resolve their remaining differences. On the other hand, if they fail to discern such gaps until one side drafts the accord, there are likely to be claims of dishonesty and recriminations.

Once the basic terms have been agreed upon and confirmed, the participants should take a few minutes to see if there is any way they can further expand the overall pie and simultaneously improve their respective positions. During both the Information Stage and the Distributive Stage, most parties have over and understated the actual value of various items for strategic purposes. As a result, Side A may have obtained several provisions Side B values more highly, while Side B got some terms Side A values more. If they can discover these inefficiencies and exchange these items, both sides should be able to improve their respective situations.

During this portion of their interaction, negotiators should look for terms they suspect may have ended up on the wrong side of the bargaining table. They should consider issues they overstated their own interest in due to the fact they thought the other side wanted them more. They should ask the opposing side if they were to concede these items, what could that side give to them. Only when it seems impossible for one side to obtain further gains without actual losses by the opposing party should the participants consider their terms final.

When negotiators explore possible exchanges during the Cooperative Stage, they should be careful not to indicate such prior deception with respect to their true values, or they risk undermining the terms already agreed upon. If their opponents begin to suspect that they misrepresented many of their interests during the earlier discussions, they may begin to think that they have been excessively dishonest. As a result, their adversaries may begin to reopen many terms and possibly destroy the opportunity for a final accord.

\section{Conclusion}

When attorneys negotiate, some assume "fixed pie" or "zero sum" situations which necessitate resorting to highly combative tactics, while others assume that each side wishes to obtain entirely different items which makes it easy for them to use integrative 
techniques to achieve mutually beneficial accords. Although many legal and commercial interactions involve cooperative issues that should be resolved efficiently to generate greater joint surpluses that can be shared by the participants, they almost always include distributive terms the parties both wish to obtain.

Many practitioners assume that opponents are either Cooperative/Problem-Solvers who are open, trusting, and wish to generate fair and efficient agreements, or Competitive/Adversarials who are closed, manipulative, and hope to achieve one-sided agreements favoring their own side. In reality, however, many proficient negotiators are Competitive/Problem-Solvers who work to achieve efficient accords, but who employ subtle distributive tactics designed to enable them to claim more of the joint surplus created. As a result, there is an inherent tension between value creation and value claiming in most legal negotiations.

During the value creation portion of interactions, participants should use the Information Stage to determine the pertinent items and the relative values placed on those terms by the different parties. Negotiators must be willing to indicate what they actually hope to obtain and the general degree to which they value those terms. Nonetheless, Competitive/Problem-Solvers are likely to over or understate the degree to which their clients want particular items to enable them to obtain a strategic advantage over naively open opponents.

Once negotiators have ascertained the various issues to be resolved, they have to use the Distributive Stage to decide how they will divide those items, which tends to be the most competitive portion of bargaining interactions. Individuals should not assume that their adversaries are altruistic persons who want to divide the items fairly. Most legal representatives will endeavor to claim more of the jointly created surplus for their own clients, and persons who fail to appreciate this reality are likely to end up with less when the interaction is concluded. 